\title{
Environmental characterization of microhabitats used by amphibians in the Tensift region of Morocco: An explanatory assessment using Artificial Neural Networks
}

\author{
Ait El Cadi Radouane, Slimani Tahar ${ }^{1}$, Ait Babram Mohamed², El Mouden El Hassan,* \\ ${ }^{1}$ Laboratory of Water, Biodiversity and Climatic Change, Department of Biology, Faculty of Sciences Sem- \\ lalia, Cadi Ayyad University. B.P 2390, Av. My Abdellah 40000, Marrakech, Morocco. \\ ${ }^{2}$ Career Center, Faculty of Sciences and Technics, Cadi Ayyad University. B.P 549, Av.Abdelkarim Elkhatta- \\ bi, Guéliz, Marrakech, Morocco. \\ *Correspondence: Phone: +212 670099312, Fax: +212 524487412, E-mail: elmouden@uca.ac.ma
}

Received: 12 April 2019; returned for review: 06 July 2019; accepted: 08 January 2020.

An adequate understanding of the relationship between amphibians and their habitat has been among the main challenges in herpetology in recent decades, particularly given the role of global change in the rapid declines of this group worldwide. Using the Artificial Neural Networks approach (ANN), we examined the environmental factors determining the occurrence of amphibians in the aquatic ecosystems in Tensift region of Morocco. We applied this modeling technique to 14 environmental factors and the presence of amphibian species collected from 40 sites. The results showed that the ANN is a useful approach to evaluate the effects of habitat factors on species occurrence. The model correctly classified all species with high performance. The best result was obtained for Bufo spinosus data, with a recognition percentage of $93.6 \%$ and a prediction performance of $99.4 \%$. Of all factors studied, altitude was key in explaining the species distribution and richness, followed by hydroperiod and conductivity, for almost all species. The importance of other factors varied according to species. Principal Component Analysis differentiated a community composed by three species of Bufonidae (Bufotes boulengeri, Sclerophrys mauritanica and Barbarophryne brongersmai) that are close to Hyla meridionalis, while Bufo spinosus, Discoglossus scovazzi and Pelophylax saharicus were influenced by other environmental factors. The results provide important new information that will support conservation decision making for the protection of amphibian populations and their habitats in the studied region.

Key words: community; environmental factors; habitat variables; occupancy; spatial distribution.

The ways environmental conditions impact species strongly influences habitat use, spatial distribution and community composition (Schoener, 1989). A detailed understanding of these interactions is therefore an essential step to have an overview on the adaptations of species to their living environments, as well as the implementation of efficient conservation and protection programs for endangered species. The impacts of environmental conditions on habitat use and spatial distribution is particularly important for amphibian fauna due to their complex life cycle (Wilbur, 1980), their dependence on wetlands for breeding and the spatial heterogeneity of the habitats they require for living (Hartel et al., 2006). Previous studies 
have revealed strong relationships between environmental parameters and richness and abundance of amphibian species across various ecoregions (CogăLNICEANU et al., 2012; OdA et al., 2016; Escoriza \& BEN Hassine, 2017; PrÉAu et al., 2018). The Artificial Neural Network (ANN) has not been previously used for this purpose in amphibians, even though this modeling technique is an efficient approach for complex non-linear data (LeK \& Guegan, 1999; Chang \& Chuang, 2013). ANN has been extensively employed in applied ecological studies for groups other than amphibians, including: predicting phytoplankton production (SCARDI, 1996), predicting fish species richness, density and biomass (BARAN et al., 1996; Brosse et al., 1999), or predicting production / biomass ratio of animal populations (BREY et al., 1996). In the present study, we conduct an analysis of the relationships between amphibians and their microhabitats in the Tensift region, Morocco, using ANN which take into account the non-linearity of data.

Most investigations of Moroccan amphibians have examined taxonomy and distribution (e.g. Bons \& Geniez, 1996; Schleich et al., 1996; BeuKema et al., 2013), while some others have studied habitat use, particularly in the northern region (EL Hamoumi et al., 2007; El Намоumi \& НimMI, 2010; Escoriza \& Ben Hassine, 2015, 2017; Escoriza et al., 2016). In order to extend our knowledge on the interaction between amphibians and their habitats in Morocco, we focused our study on the Tensift region, which provided a high diversity of habitats from wetlands (High Atlas Mountains) to arid environments (Jbilets). This work is an important contri- bution to the measurement of environmental factor effects on amphibians in the region and therefore provides tools for better conservation actions. Our objectives were i) to describe the habitat of each species using 14 environmental variables and the ANN approach, and ii) to identify the environmental variables that predict the presence of amphibian species in the aquatic habitats of the region.

\section{Materials and Methods}

\section{Study site and sampling}

This study was carried out in the Tensift watershed, located in central Morocco and covering an area of $20450 \mathrm{~km}^{2}$ (Fig. 1). The Tensift watershed is surrounded by the crest of the High Atlas Mountains (with an altitude above 4000 $\mathrm{m}$ ) in the south and the Jbilet Mountains in the north. Water from these mountains flows west across the Haouz plain. The region includes a complex landscape and topography, including escarpments and floodplains. Rainfall varies from $800 \mathrm{~mm}$ in the mountain region to $190 \mathrm{~mm}$ in the plain. The arid and semi-arid character dominates throughout the region and the sub-humid character appears at an altitude above $1500 \mathrm{~m}$. The high elevation regions receive more annual precipitation than lowlands, the latter receiving water also from snow melting coming from the mountains. Tributaries originating from the Jbilets are characterized by short spates following rainstorms. The climate of the region is highly seasonal, with irregular precipitations and occasional prolonged droughts.

From 2013 to 2015, we sampled 40 aquatic sites spread across the studied re- 


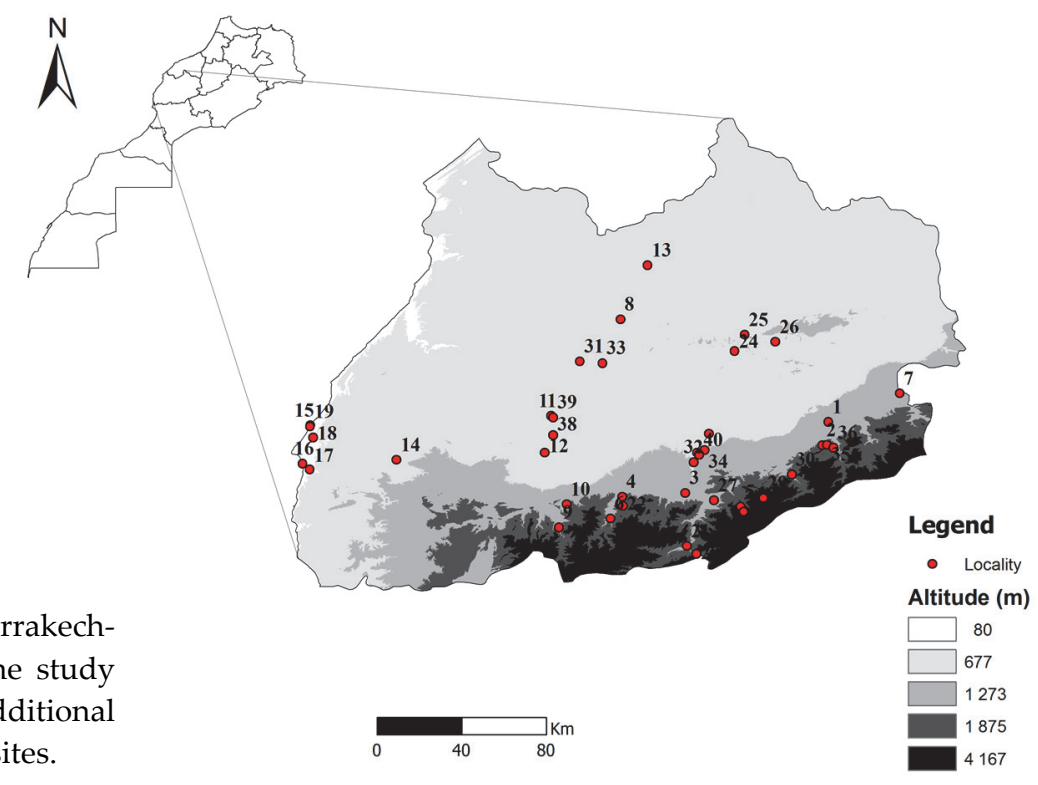

Figure 1: Map of MarrakechSafi region showing the study sites. See Table 1 for additional information about the sites.

gion (Fig. 1; Table 1). The habitats surveyed included dayas (permanent / temporary ponds), streams, rivers, lakes and irrigation systems. All samples were collected during the breeding season (April to June) when the detectability of amphibians (adults and / or larvae) was highest (SchleIch et al., 1996). We visited each site at least three times and surveyed amphibians using diurnal visual transects and active search under stones along the entire shore. We also surveyed each site for one hour during the night at every visit (listening points). We registered the detected species and assumed absent the species that were not detected during these surveys. For each locality, the habitat was evaluated using 14 environmental variables, which were selected according to regional landscape features and previously published works (SMITH et al., 2007; BatKale \& Kaya, 2009; Cogălniceanu et al., 2012; ODA et al., 2016; EscorizA \& BEN
Hassine, 2017; PréAu et al., 2018). The recorded variables were: altitude (ALT in meters above sea level), conductivity (CON in $\left.\mu S \cdot \mathrm{cm}^{-1}\right)$, which was used as a proxy for water salinity, water temperature (WT in ${ }^{\circ}$ C), air temperature (AT in ${ }^{\circ} \mathrm{C}$ ), water column depth (DEP in $\mathrm{cm}$ ), which was classified in three levels (less than $50 \mathrm{~cm}, 50-100$ $\mathrm{cm}$ and more than $100 \mathrm{~cm}$ ), type of soil around the aquatic habitat at $300 \mathrm{~m}$ (TS, which was classified as clay, sandy or rocky), type of water body (WB, classified as river, lake, pond or irrigation system), hydroperiod (HYP, classified as permanent, intermediate, rarely dry or ephemeral), nature of background (BAC, classified as sediment, pebble, sandy or rocky), type of water ecosystem (AQT, classified as running or stagnant water), type of vegetation at $300 \mathrm{~m}$ around the aquatic habitat (VEG, classified as arid steppe, shrubby or lawn), and presence or absence (binomial variables) of aquatic plants (AQP), algae 
Table 1: List of sampled localities and their amphibian species richness.

\begin{tabular}{|c|c|c|c|c|}
\hline ID & Site & Altitude (m) & Type of habitat & Species richness \\
\hline 1 & AitOurir & 896 & river, temporary & 2 \\
\hline 2 & Tidili & 896 & pond, temporary & 3 \\
\hline 3 & Amezmiz & 980 & pond, temporary & 3 \\
\hline 4 & AssifElma & 926 & pond, temporary & 2 \\
\hline 5 & Gheghaya & 1082 & river, permanent & 3 \\
\hline 6 & Adassil & 1100 & pond, temporary & 2 \\
\hline 7 & Ait Adel & 843 & lake, permanent & 4 \\
\hline 8 & Ouled Abbes & 581 & artificial pool, permanent & 2 \\
\hline 9 & Boulaaouane & 1072 & artificial pool, temporary & 1 \\
\hline 10 & Lalla Aziza & 1072 & pond, temporary & 1 \\
\hline 11 & O. Chichaoua & 333 & river, temporary & 4 \\
\hline 12 & Abaynou & 461 & pond, permanent & 1 \\
\hline 13 & Elgantour & 398 & pond, permanent & 2 \\
\hline 14 & Meskala & 414 & river, temporary & 2 \\
\hline 15 & Essaouira & 4 & lake, permanent & 3 \\
\hline 16 & Sidi Kaouki & 11 & pond, temporary & 2 \\
\hline 17 & Tidzy & 14 & river, temporary & 2 \\
\hline 18 & Oued Ksob & 20 & river, permanent & 1 \\
\hline 19 & Squala & 4 & artificial pool, permanent & 1 \\
\hline 20 & Tiganzi & 1250 & artificial pool, permanent & 5 \\
\hline 21 & Ijoukak & 1042 & river, permanent & 3 \\
\hline 22 & Igherman & 1143 & pond, temporary & 1 \\
\hline 23 & Imlil & 1534 & river, permanent & 5 \\
\hline 24 & Boukricha & 540 & river, temporary & 2 \\
\hline 25 & Jboub & 517 & artificial pool, permanent & 3 \\
\hline 26 & Jaaidate & 623 & artificial pool, temporary & 2 \\
\hline 27 & Marigha & 920 & river, temporary & 1 \\
\hline 28 & Oued N'fis & 565 & river, permanent & 3 \\
\hline 29 & Oukaimeden & 2623 & river, permanent & 6 \\
\hline 30 & Ourika & 1071 & river, permanent & 3 \\
\hline 31 & Sidi chiker & 492 & pond, temporary & 4 \\
\hline 32 & Takerkouste & 602 & lake, permanent & 2 \\
\hline 33 & Taounghast & 1196 & river, permanent & 4 \\
\hline 34 & Oumnaste & 504 & river, temporary & 1 \\
\hline 35 & Tigerdi & 1677 & pond, temporary & 2 \\
\hline 36 & Tighedouine & 1068 & river, permanent & 2 \\
\hline 37 & Tameslouht & 570 & pond, temporary & 2 \\
\hline 38 & AitHkim & 581 & river, permanent & 1 \\
\hline 39 & Chichaoua & 333 & pond, temporary & 2 \\
\hline 40 & Tiwly & 602 & river, temporary & 2 \\
\hline
\end{tabular}

(ALG) and fishes (FIS). Conductivity and water temperature were measured in situ with a multiparameter HI9829 (Hanna Instruments, Woonsocket, Rhode Island,
USA). Air temperature was measured with a digital thermometer. The average water column depth was taken as the mean value of three suc-cessive measurements from 
the shore to the centre. The presence or absence of aquatic plants, algae and fish was determined visually by scanning the surface of the aquatic habitats. All variables related to habitat characteristics were sampled between 10:00 am and 12:00 pm.

\section{Modelling techniques}

We analyzed the collected data with a multilayer perceptron, which is a class of feed-forward ANN (LeK \& Guegan, 1999). The networks are composed of a series of interconnected nodes (neurons) which receive and process input signals and potentially generate output signals (Structure of ANN is shown in Fig. 2). This technique can analyze large data sets and display relationships between the input parameters and output terms, for both linear and non-linear relationships (LeK \& Guegan, 1999). The neurons in each layer are fully interconnected by connection strengths, which express the relative importance of each input to a processing element (LeK \& Guegan, 1999).

Using SPSS Statistics 20, we built networks with a single hidden layer of one individual neuron, an input layer of 14 neurons corresponding to 14 environmental factors obtained from the 40 sites (560 data), and an output layer of two neurons corresponding to presence and absence of species. For species richness classification, the architecture of the model was the
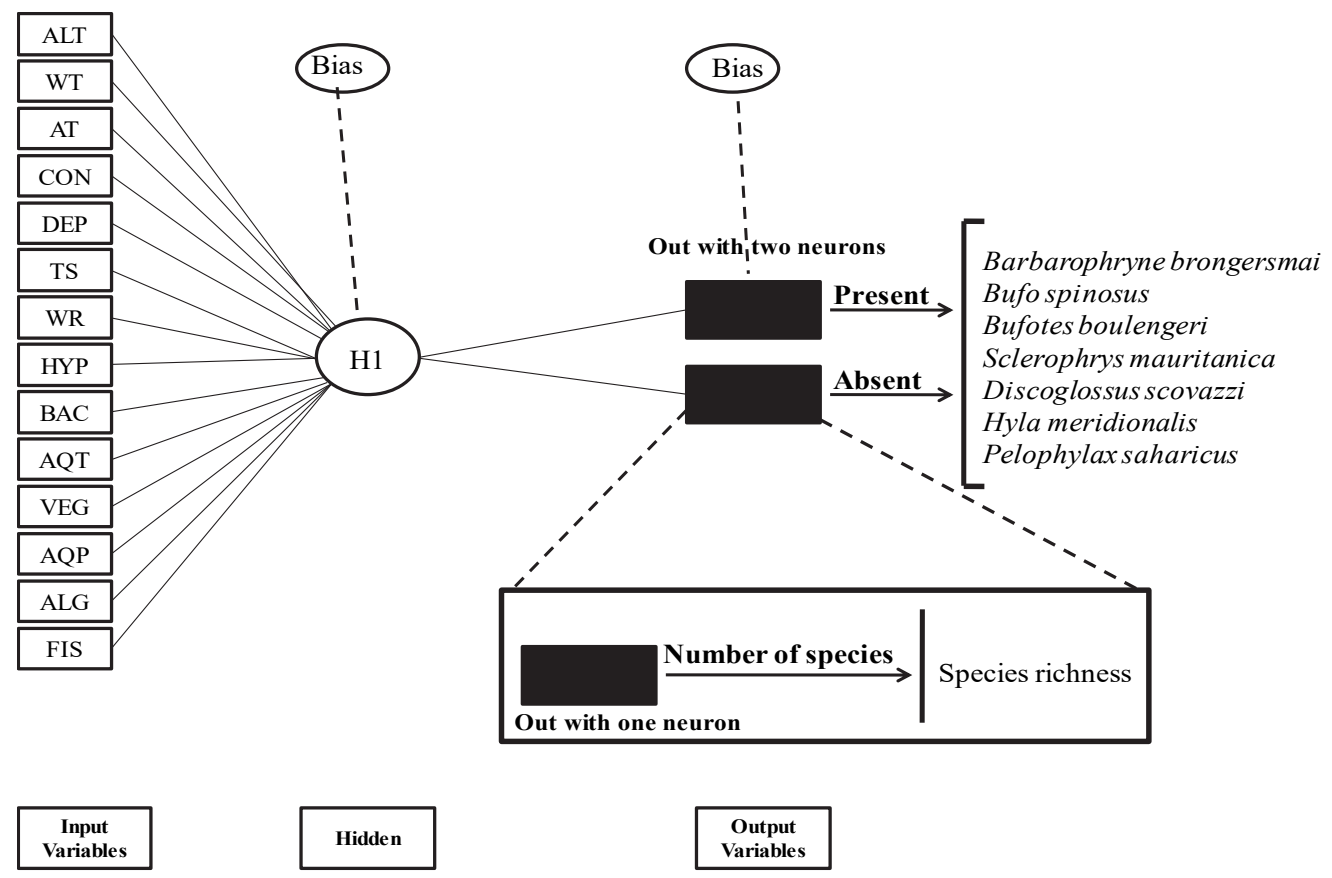

Figure 2: Structure of the used Artificial Neural Network. Fourteen input neurons corresponding to 14 independent environmental variables (see text for description of abbreviations), one hidden layer neuron (H1) and two output neurons for estimating the presence / absence of the seven amphibian species, which were afterwards predicted. For species richness, the last layer connects to the output variables with one neuron for estimating the number of species. 
same, except that the output layer was composed by a single neuron corresponding to the number of species. We used the following procedures to process the data: (1) split the data into $70 \%$ for model training and 30\% for testing; and (2) use the mean of 10 networks to evaluate the classification performances, accuracy measures and relative contribution of habitat variables.

\section{Performance of the ANN model}

To assess the classification capacity of ANN models, we considered the following accuracy measures: (i) sensitivity, defined as the proportion of presence correctly classified; (ii) specificity, defined as the proportion of absence correctly classified; (iii) over-prediction, defined as the proportion of observed absence but predicted presence; (iv) under-prediction, defined as the proportion of observed presence but predicted absence; and (v) area under the curve (AUC) of the receiver operating characteristic.

\section{Importance of habitat variables}

We used Garson's algorithm (GoH, 1995) to determine the influence of the environmental variables. The mean was used to provide the relative contribution of each habitat variable (Thuiller, 2003; Segurado \& Araujo, 2004). We assumed a given variable to be important if its contribution was greater than $7.14 \%$ (the mean value of a theoretical homogeneous distribution of all the variables; i.e., $100 \%$ of contribution / 14 variables $=7.14 \%)$ (Brosse et al., 2001). Likewise, we used the mean of the 10 ANN models to assess and visualize the distribution of all species in the environ- mental space using a Principal Component Analysis (PCA).

\section{Results}

\section{Amphibian species and diversity}

A total of seven species of amphibians, representing seven genera and four families, were found in the Tensift region with high variability in their spatial distribution. All the inventoried species correspond to amphibian taxa previously recorded in the region. The family Bufonidae was represented by four species (Barbarophryne brongersmai, Bufo spinosus, Bufotes boulengeri and Sclerophrys mauritanica), while the other families were represented each by one species (Alytidae: Discoglossus scovazzi; Hylidae: Hyla meridionalis and Ranidae: Pelophylax saharicus). Among the recorded species, B. spinosus was the rarest (only in 5\% of sampled sites, $\mathrm{N}=2$ ), while $P$. saharicus was the most common one ( $95 \%$ of sites, $\mathrm{N}=38$ ). Sclerophrys mauritanica, a species that approaches water only during the breeding season, was documented in $55 \%$ of the sites. Bufotes boulengeri and H. meridionalis were identified in 11 and 12 sites, respectively (i.e. $27.5 \%$ and $30 \%$ of sites), while D. scovazzi and B. brongersmai (two Moroccan endemic species) were present in $17.5 \%$ and $10 \%$ of sites, respectively.

The number of species per site ranged from 1 to 6 (mean \pm standard deviation: $2.43 \pm 1.24$ ). The majority of sites contained less than four species (82.5\%), and only seven sites contained 4-6 species. Those sites with more than five species were located in mountain areas. The site with the highest richness (six species) was the Oukaimeden station (2600 m). 
Table 2: Performance parameters (sensitivity, specificity, under-prediction, over-prediction and AUC) of the Artificial Neural Network models constructed using 14 input variables for each amphibian species. Values represent mean \pm standard deviation of 10 replicates.

\begin{tabular}{cccccc}
\hline Species & Sensitivity & Specificity & $\begin{array}{c}\text { Over- } \\
\text { prediction }\end{array}$ & $\begin{array}{c}\text { Under- } \\
\text { prediction }\end{array}$ & AUC \\
\hline Hyla meridionalis & $70.6 \pm 16.5$ & $91.9 \pm 7.1$ & $81.6 \pm 15.4$ & $88.6 \pm 6.5$ & $0.78 \pm 0.60$ \\
Discoglossus scovazzi & $86.7 \pm 21.9$ & $98.1 \pm 3.4$ & $92.1 \pm 13.3$ & $96.7 \pm 6.0$ & $0.95 \pm 0.62$ \\
Barbarophryne brongersmai & $78.3 \pm 23.6$ & $99.1 \pm 2.7$ & $95.0 \pm 15.8$ & $97.6 \pm 2.9$ & $0.81 \pm 0.13$ \\
Bufotes boulengeri & $77.7 \pm 14.7$ & $94.5 \pm 5.3$ & $84.7 \pm 14.2$ & $92.3 \pm 5.2$ & $0.77 \pm 0.50$ \\
Sclerophrys mauritanica & $92.1 \pm 5.2$ & $85.1 \pm 8.5$ & $88.1 \pm 7.2$ & $89.7 \pm 6.7$ & $0.87 \pm 0.54$ \\
Bufo spinosus & $100.0 \pm 0.0$ & $100.0 \pm 0.0$ & $100.0 \pm 0.0$ & $100.0 \pm 0.0$ & $0.98 \pm 0.34$ \\
Pelophylax saharicus & $100.0 \pm 0.0$ & $61.7 \pm 27.2$ & $96.5 \pm 3.0$ & $100.0 \pm 0.0$ & $0.75 \pm 0.17$ \\
\hline
\end{tabular}

\section{Performance of the ANN Model}

Several iterations of the ANN analysis were necessary to guarantee the convergence of estimated values toward the expected ones without obtaining an overfit (Gallant, 1993). With the training set of data, the performance fluctuated between 69.2 and $83.3 \%$ for 1 to 500 iterations, whereas that of the testing set increased from $40 \%$ to $69 \%$ (up to 50 iterations). After 50 iterations, the performance of the testing set fluctuated between 69 and $83.3 \%$. We stopped training of network of all species at 100 iterations in order to avoid overfitting.

We averaged the accuracy measures of the 10 model repetitions (Table 2). All AUC values were higher than 0.75 , with the best results being obtained for $B$. spinosus (mean \pm SD: $0.98 \pm 0.34$ ) and D. scovazzi $(0.95 \pm 0.62)$. The sensitivity values, reflecting the ability of the models to discriminate presences and absences, were greater than $70.8 \%$ for all species with a maximum classification of $100 \%$ obtained for B. spinosus and P. saharicus. This means that all observed presences were correctly classified. Likewise, the models returned a similarly high proportion of correctly classified absences for all species (specificity > $85 \%$ ) except for $P$. saharicus (61.7\%). We also noted that sensitivity was higher than the specificity in S. mauritanica and $P$. saharicus, while the opposite was true for less abundant species in the region. For the rarest species, B. spinosus, both accuracy measures were extremely high (100\%). Over-prediction and under-prediction values were also high (Table 2) and positive and negative results had at least $81 \%$ chance of being correct (example of H. meridionalis).

The predictive power of the different models, determined from 10 training fractions, was tested on 10 test fractions (Table $3)$. Even though the operation was repeated 10 times with different observations, standard errors calculated for each species were low (less than 20\%), showing again the stability of the network models. We obtained correct classifications for all species and the performance percentages were high, both in the training and in the testing sets (Table 3 ). The best result was obtained for B. spinosus data, with a mean 


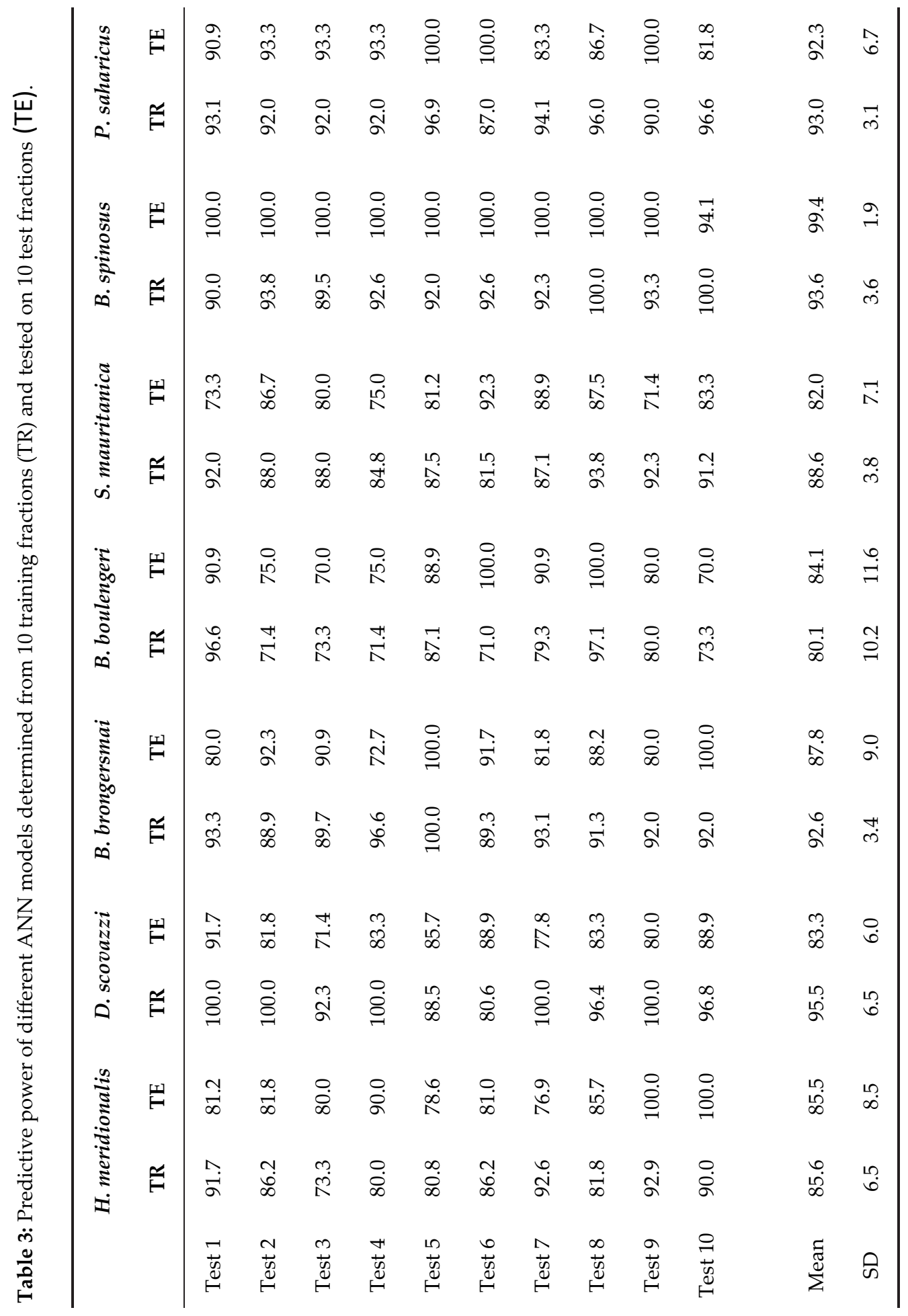


Table 4: Relative importance of the 14 input variables expressed as percentage of contribution to explain species presence and richness, obtained from Artificial Neural Networks and determined by Garson's algorithm. The most important variables for each species are highlighted in bold characters. See text for description of variable abbreviations.

\begin{tabular}{ccccccccc}
\hline $\begin{array}{c}\text { Input } \\
\text { var. }\end{array}$ & $\begin{array}{c}\boldsymbol{H} \text {. } \\
\text { meridionalis }\end{array}$ & $\begin{array}{c}\boldsymbol{D} \text {. } \\
\text { scovazzi }\end{array}$ & $\begin{array}{c}\boldsymbol{B} . \\
\text { brongersmai }\end{array}$ & $\begin{array}{c}\text { B. } \\
\text { boulengeri }\end{array}$ & $\begin{array}{c}\text { S. } \\
\text { mauritanica }\end{array}$ & $\begin{array}{c}\boldsymbol{B} \text {. } \\
\text { spinosus }\end{array}$ & $\begin{array}{c}\boldsymbol{P} . \\
\text { saharicus }\end{array}$ & $\begin{array}{c}\text { Species } \\
\text { richness }\end{array}$ \\
\hline ALT & $\mathbf{1 3 . 6 3 7}$ & $\mathbf{2 1 . 0 0 6}$ & $\mathbf{9 . 6 2 1}$ & $\mathbf{8 . 1 0 9}$ & $\mathbf{9 . 1 0 4}$ & $\mathbf{2 9 . 0 1 0}$ & $\mathbf{8 . 6 8 3}$ & $\mathbf{2 5 . 6 6 2}$ \\
AT & $\mathbf{7 . 1 9 7}$ & 6.098 & $\mathbf{9 . 7 4 2}$ & 6.461 & $\mathbf{1 5 . 7 8 7}$ & 6.550 & 5.544 & 6.334 \\
WT & 6.776 & 4.751 & 5.947 & 7.195 & 6.497 & 5.616 & $\mathbf{8 . 0 6 6}$ & $\mathbf{7 . 6 4 3}$ \\
CON & $\mathbf{9 . 0 8 1}$ & 5.262 & $\mathbf{1 0 . 4 6 0}$ & $\mathbf{7 . 8 1 8}$ & $\mathbf{1 1 . 4 3 3}$ & 6.120 & $\mathbf{1 0 . 4 3 7}$ & $\mathbf{8 . 7 4 6}$ \\
TS & $\mathbf{7 . 2 1 2}$ & $\mathbf{8 . 8 1 3}$ & 4.867 & $\mathbf{9 . 9 8 7}$ & 6.719 & 4.848 & $\mathbf{9 . 1 4 3}$ & 6.646 \\
BAC & 2.902 & $\mathbf{8 . 7 4 0}$ & 4.792 & 4.814 & 4.294 & 4.033 & $\mathbf{7 . 8 6 6}$ & 4.595 \\
AQT & 3.888 & 1.595 & 6.571 & 5.870 & 5.905 & 4.337 & 6.486 & 3.629 \\
HYP & $\mathbf{1 3 . 7 9 8}$ & $\mathbf{7 . 3 7 7}$ & $\mathbf{7 . 1 7 9}$ & $\mathbf{1 0 . 7 7 2}$ & $\mathbf{1 0 . 7 7 7}$ & 6.933 & 6.763 & 7.008 \\
WR & 6.554 & 4.876 & 6.325 & 5.337 & 6.420 & 2.835 & 4.533 & 4.923 \\
DEP & 3.825 & $\mathbf{1 2 . 3 0 9}$ & $\mathbf{7 . 9 1 6}$ & 6.384 & 5.198 & 5.421 & $\mathbf{7 . 8 0 2}$ & 5.396 \\
AQP & 4.339 & 6.142 & 4.236 & 2.446 & 3.368 & 2.825 & $\mathbf{8 . 8 4 4}$ & 3.500 \\
FIS & 6.529 & 4.841 & 6.394 & $\mathbf{8 . 9 5 7}$ & 4.702 & 5.391 & 4.501 & 5.063 \\
ALG & 5.850 & 2.518 & 5.467 & $\mathbf{1 0 . 2 7 5}$ & 4.084 & 1.604 & 4.125 & 5.423 \\
VEG & $\mathbf{8 . 4 1 1}$ & 5.672 & $\mathbf{1 0 . 4 8 5}$ & 5.574 & 5.712 & $\mathbf{1 4 . 4 7 8}$ & 7.206 & 5.433 \\
\hline
\end{tabular}

recognition percentage of $93.6 \%$ and a prediction performance of $99.4 \%$. The poorest result was obtained for $B$. boulengeri, with $80.1 \%$ recognition percentage and $84.1 \%$ prediction performance. The values for the other species are comprised between 85.5 and $95.5 \%$, and between 82.0 and $92.3 \%$ for recognition percentage and prediction performance, respectively. These results indicated an excellent classification performance of the ANN model.

\section{Importance of habitat variables}

According to the ANN model, amphibian habitats in the region were defined by a complex combination of different habitat characteristics (Table 4). Species presence was influenced by a wide variety of environmental parameters as the case of $P$. saharicus and $B$. boulengeri. The contribution of the 14 variables ranged from 1.6 to $21 \%$ in the ANN models for the different species (Table 4). The results emphasize the importance of five variables: altitude, conductivity, hydroperiod, type of soil and vegetation. Altitude was the only habitat factor that affected the distribution patterns of all species. It was the most important factor predicting the presence of $B$. spinosus (explaining a $29 \%$ of the species presence) and D. scovazzi (21\%). In fact, $B$. spinosus was rare and was found at high altitude sites like Imlil (1534 m) and Oukaimeden $(2600 \mathrm{~m})$, whereas D. scovazzi was detected in seven out of the eight sampled sites at an altitude above $850 \mathrm{~m}$. According to the models, vegetation was the only other factor affecting the distribution of B. spinosus. The presence of D. scovazzi was affected by water depth (> 50 $\mathrm{cm}$ ), type of soil (clay) and nature of background (sediment). Altitude was also a 


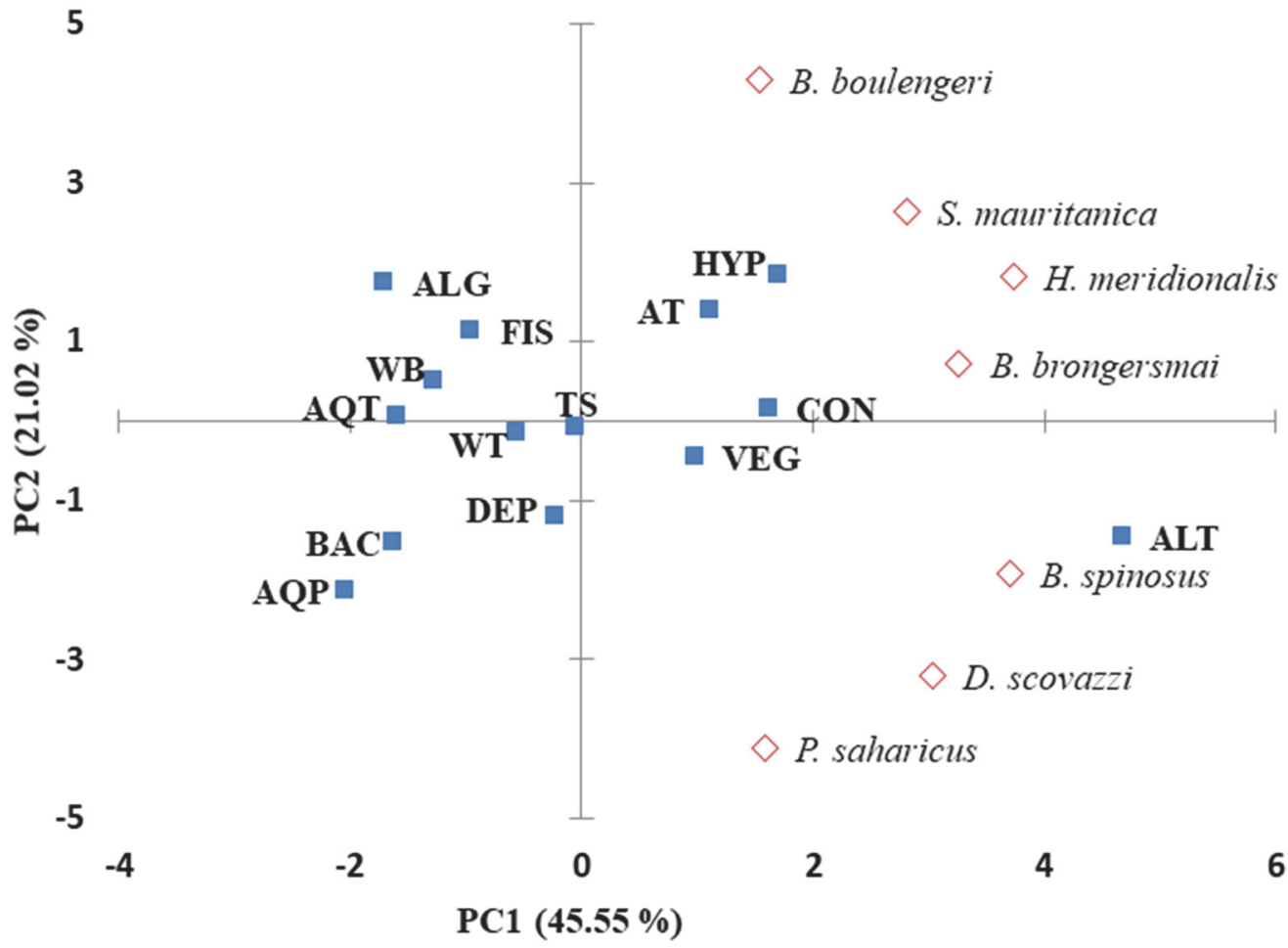

Figure 3: Distribution of the seven amphibian species and the 14 environmental variables relative to the first two axes (Principal Components, PC1 and PC2) of the Principal Component Analysis. For each species, we used the mean of the ten ANN models to assess the spatial distribution. See article text for definition of the environmental variables.

determinant factor for the presence of $H$. meridionalis (13.6\%), which was found in permanent or intermediate waters. The results showed that $B$. brongersmai distribution was essentially affected by conductivity, with its presence localized in the arid steppe. The presence of S. mauritanica was related to air temperature, conductivity and hydroperiod. The last two species, $B$. boulengeri and $P$. saharicus, were dependent on a variety of factors (seven and eight factors, respectively), with hydroperiod and conductivity as the most im- portant ones, respectively.

The results of the contribution of the 14 environmental variables on the amphibian richness in the Tensift region showed that altitude, conductivity, water temperature and hydroperiod were the most influencing factors $(49.05 \%)$. The greatest contribution $(25.66 \%)$ was attributed to altitude. In fact, the specific richness follows an altitudinal gradient with the highest number of species (six) found in the humid area of Oukaimeden at $2600 \mathrm{~m}$. 


\section{Spatial distribution and species community}

The first and second axis of the PCA conducted to visualize the distribution of all species and to understand species communities accounted for 45.6 and $21 \%$ of the total variation, respectively (Fig. 3). The first axis was positively correlated with altitude, vegetation, conductivity, hydroperiod and air temperature and negatively correlated with the rest of the variables. Overall, this axis described the transition from mountains to plains. Bufo spinosus showed a strong positive correlation with this axis, as it was found only in the humid mountain zones. The second axis was positively correlated with hydroperiod and negatively to aquatic plants and depth. Overall, the second axis described the transition from temporary to permanent waters. Discoglossus scovazzi and $P$. saharicus showed a negative correlation with this axis, whereas species belonging to Bufonidae family were positively correlated to this axis (mostly found in arid habitats).

\section{Discussion}

The Tensift region is an extensive and heterogeneous area with multiple environmental factors that shape amphibian distribution. This study demonstrated that ANN can be used to predict the presence and absence of amphibian species in the Tensift region based on environmental characteristics of the habitats. The results agree with existing ecological data available for the species found in the sampled sites. According to these results, the ANN may constitute an efficient tool to explain the presence of amphibians in the study region.
Elevation has been found to be a highly influential factor for species distribution. A strong relationship between elevation and species richness was previously reported in amphibians (EscorIzA \& BEN HAssine, 2017) and in a variety of other taxa (McCaIn, 2005). It has been found that amphibian species diversity increases with elevation, as a result of complex concomitant changes in temperature and precipitation regime leading to less evaporation and more persistent water bodies (Benítez et al., 2017). Altitudinal variability is associated with variation in climatic, biological and geographical conditions, which ultimately affect species richness (RAHBeK, 1995; WhitTaKer et al., 2001).

Other than elevation, the variables that characterized water bodies (e.g. conductivity and hydroperiod), were found to be the most influential for the presence of amphibians in the study sites. All species colonized environments with low conductivity, except $P$. saharicus and $B$. boulengeri, which were found in water with high conductivity in coastal areas (Sidi Kaouki and Tidzy). Adults and larvae of B. boulengeri have been previously reported to be very tolerant to salinity (SCHLEICH et al., 1996; EL Hамоuм et al., 2007). In general, most amphibians are sensitive to salinity because their skin and egg membranes are highly permeable and have poor osmoregulatory ability (WeLLS, 2007).

As expected, the presence of B. spinosus is strongly influenced by altitude ( $29 \%$ of contribution). This result is consistent with other reports of the ecology of this species in Morocco and North Africa (Bons \& GENiez, 1996; Schleich et al., 1996; El Hamoumi \& Himmi, 2010; Escoriza \& Ben Hassine, 
2017). In Morocco, the distribution range of $B$. spinosus is limited to the humid localities on the Mediterranean and Atlantic coasts, remaining at mountain sites in the rest of the country (SCHLeich et al., 1996). In North Africa, the species colonizes only the niches under cool and humid climates (Escoriza \& Ben Hassine, 2017) and reaches an altitude of $2750 \mathrm{~m}$, which represents the highest elevation for amphibians in the region (Bons \& Geniez, 1996). Living at high elevations offers access to permanent water bodies, which is important for this species (Diaz-Paniagua, 1990; El HamouMI et al., 2007).

Altitude is also an important factor for the distribution of D. scovazzi and H. meridionalis. Their frequent presence at high altitudes is likely linked to their preference for permanent or semi- permanent waters and to the presence of vegetation around water bodies, although a previous study found that $D$. scovazzi typically occurred in ephemeral pools (El Намоuмi et al., 2007). Our findings are more in line with the ecological needs of species, like D. scovazzi, with large tadpoles that require longer hydroperiods to complete their development (KulKarni et al., 2011; Escoriza \& Ben Hassine, 2017). The distribution ranges of H. meridionalis and D. scovazzi in Morocco also indicate a preference for permanent water (Bons \& GENIEz, 1996; SCHLEICH et al., 1996; Mediani et al., 2015), despite differences in the ecological requirements of adults (El Hamoum et al., 2007). PasTEUR \& Bons (1959) also noted the lack of a satisfactory explanation for the distribution of these two species.

The presence of $H$. meridionalis at low elevation sites of Tensift region is very limited, due to the species preference for permanent waters and abundant vegetation, as reported by other authors (SChleich et al., 1996; FernándezCardenete et al., 2000). Nevertheless, in contrast to its common name (Mediterranean tree frog), the presence of this species is not always linked to abundant vegetation. In the southern marginal zone, as the Anti Atlas region, the species occurrs in arid areas near temporary streams characterized by little vegetation (Beukema et al., 2013).

Barbarophryne brongersmai was found primarily in sites at low altitude and arid steppes, exclusively in temporary ponds. These results are in accordance with its ecological behavior. Barbarophryne brongersmai is a small Moroccan endemic anuran (body size about $5 \mathrm{~cm}$ ) occurring particularly in the south of the High Atlas, in semi-arid to desert environments (Bons \& Geniez, 1996; Schleich et al., 1996). It is considered as the Moroccan amphibian species better adapted to aridity and temporary aquatic habitat availability. A study of B. brongersmai skeletal structure pointed out unique features that might be due to the rapid larval development associated with ephemeral ponds (Delfino et al., 2009). Other morphological traits, like flattening of vertebrae, horizontal development in the sacral lateral apophysis and reduction of ridges in the vertebral neural arches, are thought to be adaptations that help this species to survive in small crevices (Doglio et al., 2010). In the study area, which constitutes the northern limit of its distribution, B. brongersmai is limited to arid zones in the Haouz, Jbilets and Essaouira regions. 
Bufotes boulengeri and P. saharicus were found to tolerate a wide variety of environmental parameters. These two species are habitat-generalists and breed in a broad range of aquatic habitats (PAsteur \& Bons, 1959; Bons \& Geniez, 1996; Schleich et al., 1996; Еl Намоumi et al., 2007; El Hамоumi \& Нiмmi, 2010). Bufotes boulengeri has been found primarily in temporary habitats, where it lives frequently in sympatry with $S$. mauritanica. It is resistant to drought (Schleich et al., 1996). The other opportunistic species, $P$. saharicus, has been found to be strictly aquatic in permanent natural and man-made water bodies with a preference for water depths higher than $50 \mathrm{~cm}$. It colonizes both stagnant and running water bodies. In the Tensift region, its distribution seems to be continuous and almost homogeneous, with high abundance at high altitude. This finding agrees with what has been reported for the species in the north of Morocco.

The toad, S. mauritanica, was common in our study sites and showed a continuous distribution. The species inhabits almost all types of landscapes in the Mediterranean region, and is considered as the second most common amphibian in the Maghreb after P. saharicus (SCHLeich et al., 1996). In our study, S. mauritanica occurred in most still or slow-moving water bodies with low conductivity. It is the only toad found in running waters, often at high densities (El Hamoumi et al., 2007).

Our results revealed multiple communities of amphibians whose presence and absence are shaped by similar ecological factors. One of the main communities identified was composed of B. brongersmai, $B$. boulengeri and S. mauritanica. This group corresponds to the lentic-benthic type described by Escoriza \& Ben Hassine (2017) on the basis of morphological characters of larvae. According to these authors, the occurrence of species with specific morphological characteristics of larvae in the group was influenced by the aridity. Increased aridity is associated with unstable hydrological regimes, which possibly favours species with small benthic tadpoles, such as xeric Bufonidae.

In conclusion, the ANN approach worked well for the analysis of the collected data and the results were in accordance with existing knowledge for the studies species. The ANN models allowed us the determination of the environmental factors that shape distribution of each species, with the altitude as the most important one. Conductivity and hydroperiod also influenced the presence of most studied species. However, the measured environmental factors could not explain all variations in species presence and richness. Other factors that were not measured in this study, such as the size of the water bodies, as well as broader ecosystem health and pollution from agricultural chemicals, likely impact amphibian populations as well. These factors must be included in future studies to better describe the habitat preferences of amphibian species.

\section{Acknowledgement}

We thank the "Haut Commissariat aux Eaux et Forêts et à la Lutte Contre la Désertication (HCEFLCD)" for the Permit to work on the field. This research was supported by Project [ICGVSA] founded by the Hassan II Academy of Sciences and 
Technology. We thank A. Abbad (Cadi Ayyad University) and Bronwen Powell (Penn State University) for checking the English language. We also thank the two referees for their valuable comments and their suggestions for improving the document.

\section{ReFERENCES}

Bapkale, E. \& Kaya, U. (2009). Richness and distribution of amphibian species in relation to ecological variables in western Aegean region of Turkey. Ekoloji 18: 25-31.

Baran, P.; LeK, S.; Delacoste, M. \& Belaud, A. (1996). Stochastic models that predict trout population density or biomass on a mesohabitat scale. Hydrobiologia 337: 1-9.

Benítez, M.; Romero, D.; Chirosa, M. \& Real, R. (2017). Eco-geographical characterization of aquatic microhabitats used by amphibians in the Mediterranean Basin. Animal Biodiversity and Conservation 40: 27-50.

Beukema, W.; De Pous, P.; Donaire-Barroso, D.; Bogaerts, S.; Garcia-Porta, J.; Escoriza, D.; Arribas O.; El Mouden H. \& CarRANZA, S. (2013). Review of the systematics, distribution, biogeography and natural history of Moroccan amphibians. Zootaxa 3661: 1-60.

Bons, J. \& Geniez, P. (1996). Amphibiens et Reptiles du Maroc (Sahara Occidental Compris): Atlas Biogéographique. Asociación Herpetológica Española, Barcelona, Spain.

Brey, T.; Jarre-Teichmann, A. \& Borlich, O. (1996). Artificial neural network versus multiple linear regression: Predicting P/B ratios from empirical data. Marine Ecology Progress Series 140: 251-256.

Brosse, S.; Guegan, J.F. Tourend, J.N. \& LeK, S. (1999). The use of artificial neural networks to assess fish abundance and spatial occupancy in the littoral zone of mesotrophic lake. Ecological Modelling 120: 299-311.

Brosse, S.; LeK, S. \& Townsend, C.R. (2001). Abundance, diversity, and structure of freshwater invertebrates and fish communities: An artificial neural network approach. New Zealand Journal of Marine and Freshwater Research 35: 135-145.

Chang, Y.-H. \& Chuang T.-F. (2013). A study of using grey system theory and artificial neural network on the climbing ability of Buergeria robusta frog. Open Journal of Ecology 3: 83-93.

Cogălniceanu, D.; Băncilă, R.; Plăıiaşu, R.; Samoilă, C. \& Hartel, T. (2012). Aquatic habitat use by amphibians with specific reference to Rana temporaria at high elevations (Retezat Mountains National Park, Romania). Annales de Limnologie - International Journal of Limnology 48: 355-362.

Delfino, M.; Doglio, S.; Roček, Z.; Seglie, D. \& Kabiri, L. (2009). Osteological peculiarities of Bufo brongersmai (Anura: Bufonidae) and their possible relation to life in an arid environment. Zoological Studies 48: 108-119.

Diaz-Paniagua, C. (1990). Temporary ponds as breeding sites of amphibians at a locality in southwestern Spain. Herpetological Journal 1: 447-453.

Doglio, S.; Seglie, D.; Slimani, T.; El Mouden, E.H.; Kabiri, L. \& Delfino, M. (2010). The Brongersma's toad (Bufo brongersmai, Hoogmoed 1972): a summary of the new data on morphology, ecology, distribution and population dynamics, In L. Di Tizio, A.R. Di Cerbo, N. Di Francesco \& A. Cameli (eds.) Atti VIII Congresso Nazionale Societas Herpetologica Italica (Chieti, 22-26 Settembre 2010). Ianieri Edizioni, Pescara, Italy, pp. 183-188.

El Hamoumi, R. \& Himmi, O. (2010). Distribution et état des lieux des peuplements d'Amphibiens dans le complexe de zones humides du bas Loukkos (Larache, Maroc). Bulletin de l'Institut Scientifique de Rabat, Section Sciences de La Vie 32: 95-100.

El Hamoumi, R.; Dakкi, M. \& Thevenot, M. (2007). Etude écologique des larves d'anoures du Maroc. Bulletin de l'Institut Scientifique de Rabat, Section Sciences de la Vie 29: 27-34. 
Escoriza D. \& Ben Hassine, J. (2015). Niche partitioning at local and regional scale in the North African Salamandridae. Journal of Herpetology 49: 276-283.

Escoriza, D. \& Ben Hassine, J. (2017). Diversity of guilds of amphibian larvae in northwestern Africa. PLoS ONE 12: 1-18.

Escoriza D.; Ben Hassine J. \& Boix D. (2016). Niche conservatism determines the occurrence of allopatric populations of Hyla meridionalis in different biogeographical scenarios. Salamandra 52: 243-254.

Fernández-Cardenete, J.R.; Luzón-Ortega, J.M.; Pérez-Contreras, J.; Tierno, J.M. \& Figueroa, D. (2000). Revisión de la distribución y conservación de los anfibios y reptiles en la provincia de Granada (España). Palabras 11: 77-104.

Gallant, S.I. (1993). Neural Network Learning and Expert Systems. MIT Press, London, UK.

GoH, A.T.C. (1995). Back-propagation neural networks for modeling complex systems. Artificial Intelligence in Engineering 9: 143151.

Hartel, T.; Demeter, L.; Cogalniceanu, D. \& Tulbure, M. (2006). The influence of habitat characteristics on amphibian species richness in two river basins of Romania, In $\mathrm{M}$. Vences, J. Köhler, T. Ziegler \& W. Böhme (eds.) Herpetologia Bonnensis II: Proceedings of the 13th Congress of the Societas Europaea Herpetologica. Societas Europaea Herpetologica, Bonn, Germany, pp. 47-50.

Kulkarni, S.S.; Gomez-Mestre, I.; Moskalik, C.L.; Storz, B.L. \& Buchrolz, D.R. (2011). Evolutionary reduction of developmental plasticity in desert spadefoot toads. Journal of Evolutionary Biology 24: 2445-2455.

LeK, S. \& Guegan, J.F. (1999). Artificial neural network as a tool in ecological modelling, an introduction. Ecological Modelling 120: 6573.

McCain, C.M. (2005). Elevational gradients in diversity of small mammals. Ecology 86: 366 $-372$.

Mediani, M.; Brito, J.C. \& FAHD, S. (2015). Atlas of the amphibians and reptiles of northern Morocco: updated distribution and patterns of habitat selection. Basic and Applied Herpetology 29: 81-107.

Oda, F.H.; Batista, V.G.; Gambale, P.G.; Mise, F.T.; De Souza, F.; Bellay, S.; Ortega J.C.G. \& Такемото, R.M. (2016). Anuran species richness, composition, and breeding habitat preferences: A comparison between forest remnants and agricultural landscapes in Southern Brazil. Zoological Studies 55: 1-14.

Pasteur, G. \& Bons, J. (1959). Les Batraciens du Maroc. Travaux de l'Institut Scientifique Chérifien, Série Zoologie 17: 1-241.

Préau, C.; Trochet, A.; Bertrand, R. \& IsselinNondedeu, F. (2018). Modeling potential distributions of three European amphibian species comparing ENFA and Maxent. Herpetological Conservation and Biology 13: 91104.

RAнBEк, C. (1995). The elevational gradient of species richness: a uniform pattern? Ecography 18: 200-205.

SCARDI, M. (1996). Artificial neural networks as empirical models for estimating phytoplankton production. Marine Ecology Progress Series 139: 289-299.

Schleich, H.; Kastle, W. \& Kabisch, K. (1996). Amphibians and Reptiles from North Africa. Koeltz Scientific Publications, Königstein, Germany.

Schoener, T.W. (1989). Food webs from the small to the large. Ecology 70: 1559-1589.

Segurado, P. \& Araujo M.B. (2004). An evaluation of methods for modelling species distributions. Journal of Biogeography 31: 15551568.

Smith, M.J.; Schreiber, E.S.G.; Scroggie, M.P.; Kohout, M.; Ough, K.; Potts, J.; Lennie, R.; Turnbull, D.; Jin, C. \& Clancy, T. (2007). Associations between anuran tadpoles and salinity in a landscape mosaic of wetlands impacted by secondary salinisation. Freshwater Biology 52: 75-84.

Thuiller, W. (2003). BIOMOD-optimizing predictions of species distributions and project- 
ing potential future shifts under global change. Global Change Biology 9: 1353-1362.

Wells, K.D. (2007). The Ecology and Behavior of Amphibians. The University of Chicago Press, Chicago, Illinois, USA.

Whittaker, R.J.; Willis, K.J. \& Field, R. (2001).
Scale and species richness: towards a general, hierarchical theory of species diversity. Journal of Biogeography 28: 453-470.

Wilbur, H.M. (1980). Complex life cycles. Annual Review of Ecology and Systematics 11: 6793. 